\title{
Perception of preventive care and readiness for lifestyle change in rural and urban patients in Poland: a questionnaire study
}

\author{
Maciek Godycki-Cwirko, 2A-F, Lech Panasiuk ${ }^{3, E-F}$, Carlos Brotons ${ }^{4, A, E-F}$, Mateja Bulc ${ }^{5,6 E-F}$, \\ Izabela Zakowska ${ }^{1, C-F}$ \\ ${ }^{1}$ Centre for Family and Community Medicine, Medical University, Lodz, Poland \\ ${ }^{2}$ Division of Public Health, Faculty of Medical Sciences, Medical University, Lodz, Poland \\ ${ }^{3}$ Institute of Rural Health, Lublin, Poland \\ ${ }^{4}$ Primary Health Care Center, Sardenya, Barcelona, Spain \\ ${ }^{5}$ Department of Family Medicine, Medical Faculty of Ljubljana University, Ljubljana, Slovenia \\ ${ }^{6}$ Community Health Center, Derčeva 5, SI 1000 Ljubljana, Slovenia \\ A - Research concept and design, B - Collection and/or assembly of data, C - Data analysis and interpretation, \\ $D$ - Writing the article, E-Critical revision of the article, $F$ - Final approval of article
}

Godycki-Cwirko M, Panasiuk L, Brotons C, Bulc M, Zakowska I. Perception of preventive care and readiness for lifestyle change in rural and urban patients in Poland: a questionnaire study. Ann Agric Environ Med. doi: 10.26444/aaem/81393

\begin{abstract}
Introduction and objective. The idiosyncrasies of rural health demand further research to instigate rural health initiatives and to monitor progress in rural health care. In 2008, a study examined health-related behaviour, perception of importance of preventive interventions, readiness to change lifestyle and willingness to receive support from GPs, according to gender and place of residence.

Materials and method. A cross-sectional survey was conducted among patients who visited any of ten randomly-selected general practices in Poland.

Results. Four hundred patients were enrolled: $50 \%$ from rural areas, $50.3 \%$ were females; $23.8 \%$ declared a primary level of education ( $35 \%$ rural vs. $12.5 \%$ urban) respondents; the median age was 50 years (IQR=18), The predicted means for prevention importance scores for rural residents were 0.623 and for urban residents -0.682 . Place of residence had a significant effect on the importance of prevention $(p<0.05 ; \mathrm{ICC}=0.048)$. Area and gender have a statistically significant effect on preventive behaviour importance scores $(\mathrm{p}<0.05$; ICC $=0.0526)$. Patient expectations of individual counselling by GPs were highest for eating habits $-35.5 \%$ rural vs. $16 \%$ urban residents $(p<0.0001)$.

Conclusions. Patient importance scores for prevention were associated with residence and gender. The villagers attached less importance to prevention. They also declared less willingness to change their lifestyle. Women had higher scores regarding prevention than men. More rural respondents would like to receive individual counselling from their GP regarding eating habits, physical activity, body weight, giving up smoking and safe alcohol use. Urban respondents were more likely to expect leaflets from their GPs on normalizing body weight.
\end{abstract}

\section{Key words}

general practice, patients, preventive medicine, rural, urban, Poland, lifestyles

\section{Acronyms}

d.f. - degree of freedom; EUROPREV - European Network for Prevention and Health Promotion in Family Medicine and General Practice; GP - general practitioner; ICC - intraclass correlation coefficient; IQR - interquartile range; LR - Likelihood ratio test statistics; mean.pred - the predicted mean; ref. cat. - reference category; RI - random intercept model; VC variance component; VPC - variance partition coefficient

\section{INTRODUCTION}

The World Organization of General Practitioners/Family Physicians ('WONCA') acknowledged the special problems existing in rural health and called for research to instigate rural health initiatives and to monitor progress in rural health care [1]. Studies showed significant differences in the overall health care assessment between rural and urban populations [2,3]. Geographic accessibility has been shown

Address for correspondence: Izabela Zakowska, Centre for Family and Community Medicine, Medical University of Lodz, Kopcinskiego 20, 90-153 Lodz, Poland E-mail: izabela.zakowska@umed.lodz.pl

Received: 06.12.2017; accepted: 20.12.2017; first published: 22.12.2017 to be one of the barriers to accessing health services [4]. A study in the USA found that residents in rural counties reported significantly lower scores in health behaviour, morbidity factors, clinical care and the physical environment [5]. It has been shown that geographical location and limited availability of care represent barriers to accessing health services by rural residents [2]. Access to health facilities varies according to place of residence [6, 7], and another study has found that the rural population is more likely to buy drugs for medical treatment [8]. It has been shown that women living in areas with limited access to health care are more likely to be diagnosed with late-stage breast cancer [9].

The aim of the study was to determine whether patient knowledge, attitudes and beliefs towards health, preventive 
care, willingness to change their lifestyle and expectations for support from GPs in Poland are associated with their area of residence. With this in mind, the present study examined the influence of place of residence on aspects of preventive care, based on the 2008 study European Network for Prevention and Health Promotion in Family Medicine and General Practice (EUROPREV).

\section{OBJECTIVES}

To investigate whether patient perceptions of health-related behaviour, the need for preventive interventions, readiness to change lifestyle and willingness to receive support from GPs depend on gender and rural or urban place of residence in Poland.

\section{MATERIAL AND METHODS}

\section{Sample}

Data were obtained from the European Network for Prevention and Health Promotion in Family Medicine/General Practice (EUROPREV; http://europrev.woncaeurope.org/) crosssectional survey performed in 22 European countries, described in detail elsewhere [10]. A subset of data collected in 10 primary care practices in Poland was used; the practices were randomly selected from a list of training practices with at least 2,500 patients each, stratified by rural and urban location. Each practice was requested to recruit, respectively, 40 consecutive adult patients $(n=400)$ stratified by gender and age. Patients attending GP consultations for any reason, on any day of the week, between September 2008 - September 2009 were eligible. Data collection was self-administered. Research assistants checked the anonymous questionnaires to ensure completeness. These were hierarchical 2-level data with patients nested within practices. The sample was representative of the Polish population stratified for age, gender and area of residence. These areas were formally classified as rural or urban. Rural areas included units of compact or dispersed settlements functioning to provide agricultural or related services, or tourism, with no rights or status of a town, nor possessing any local community facilities, such as a town hall or public offices. Urban areas included settlements with concentrated housing and the rights or the status of a town, according to the provisions of various laws [11].

\section{Questionnaire and data}

The questionnaire has been presented in detail elsewhere [10]. The first section was related to the socio-demographic characteristics of the participants. The second concerned patient health-related behaviour, obtaining information on eating habits, physical activity, smoking and alcohol consumption, as well as screening for cervical and breast cancer in the women. The third section concerned the importance of preventive behaviour declared by the patients; and the fourth readiness for action, confidence in access and to interventions and plan for change.

\section{Statistics}

Statistica version 12 (Statsoft, Inc.) and MLwiN (Version 2.24, Centre for Multilevel Modelling, University of Bristol, UK) were used for statistical analysis. Missing data was excluded from the analysis. Variables were coded into the categories and cross tables of pre-selected variables calculated for total respondents and those of rural and urban areas. To identify variables associated with setting (rural vs. urban), the Chisquare test and the Chi-square test with Yates correction for a small number of samples were employed. The answers were scored as 0 ('not important'), 1 ('of slight importance'), 2 ('important') or 3 ('very important'). Scores were calculated for all questions regarding perception of importance of preventive care (prevention importance scores) for the health of the respondent (separately for genders: 9 interventions for men and 11 for women) and scaled to a range of values between $0-1$. Higher prevention importance scores indicated perceived higher importance of preventive care, with 1 as the maximum score. Variables associated with place of residence were identified using the $\chi^{2}$ test. Normality of the data distribution was examined using the Shapiro-Wilk test. The results were presented as number (\%) of responses, median, interquartile range (IQR), range (min., max.) or differences, and predicted means with 95\% CI; p-values of 0.05 or less were considered statistically significant.

To identify the association between prevention scores with area of residence and gender, multilevel models for continuous responses were fitted in MLwiN. The variance partition coefficient (VPC) and intraclass correlation coefficient (ICC) were calculated. The intercepts for differences from the overall mean and predicted means (across practices) were calculated with corresponding 95\% confidence intervals (CIs).

\section{RESULTS}

\section{Sociodemographic characteristics}

Four hundred adult patients completed the questionnaires, no participants were excluded from the analysis. Of all the respondents, 50\% were from rural areas and 50.3\% were female. The median age was $50(\mathrm{IQR}=18)$ years for all respondents and in both residential areas.). More demographic details are shown in Table 1.

\section{Health related behaviour}

Of all respondents, $42.8 \%$ had visited their general practice once or twice in the previous year: $36 \%$ in rural areas vs. $49.5 \%$ in urban areas.

Thirty percent of all respondents declared that they currently smoke: $29 \%$ rural and $31 \%$ urban. Considering gender, $37.0 \%$ of rural men and $37.4 \%$ of urban men declared current smoking, compared to $21 \%$ of rural women and $24.8 \%$ of urban women. Four percent of total respondents were risky drinkers: $4.5 \%$ rural and 3.5\% urban. In addition, $24.2 \%$ declared the wish to receive support/advice from their GP to increase physical activity: $29.5 \%$ rural and $18.8 \%$ urban. More detailed data, including healthy eating and exercise status are presented in Table 2.

\section{Importance of preventive behaviour}

Compared to $70.5 \%$ of rural respondents who declared that their regular physical activity was important for health, 89\% of urban respondents made the same declaration. Normal body weight was declared as important by $80.5 \%$ rural vs. $92 \%$ urban respondents, respectively. The importance of not smoking and safe alcohol use, or no alcohol use at all, was 
Table 1. Socio-demographic characteristics by area.

\begin{tabular}{|c|c|c|c|}
\hline Characteristics & Respondents n (\%) & Rural n (\%) & Urban n (\%) \\
\hline Population & $400(100)$ & $200(50.0)$ & $200(50.0)$ \\
\hline Female & $201(50.3)$ & $100(50.0)$ & $101(50.5)$ \\
\hline Male & $199(49.8)$ & $100(50.0)$ & $99(49.5)$ \\
\hline Age [in years]: median (IQR) & $50.0(18.0)$ & $50.0(17.0)$ & $50.0(20.5)$ \\
\hline \multicolumn{4}{|l|}{ Highest level of education: } \\
\hline Secondary & $208(52.0)$ & 99 (49.5) & $109(54.5)$ \\
\hline Tertiary & $97(24.3)$ & $31(15.5)$ & $66(33.0)$ \\
\hline \multicolumn{4}{|l|}{ Marital status: } \\
\hline married or living with a partner & $292(73.2)$ & $149(74.5)$ & $143(71.9)$ \\
\hline not married, nor living with a partner & $40(10.0)$ & $20(10.0)$ & $20(10.1)$ \\
\hline Widowed & $23(5.8)$ & $12(6.0)$ & $11(5.5)$ \\
\hline \multicolumn{4}{|l|}{ Current employment status: } \\
\hline employed/self-employed & $255(63.8)$ & $119(59,5)$ & $136(68.0)^{* *}$ \\
\hline Pensioner & $103(25.8)$ & $51(25,5)$ & $52(26.0)$ \\
\hline Unemployed & $42(10.5)$ & $30(15.0)$ & $12(6.0)$ \\
\hline
\end{tabular}

$*$ - $p<0.05 ; * *_{-}-p<0.01 ; * * *_{-}-p<0.001$;

for living area comparison, Chi-square test and Chi-square test with Yates correction was employed for a small number of samples.

'What is your current employment situation?' - group with a small number of samples 'Unemployed' including ='Student' + 'Housewife/husband or equivalent'+ 'Unemployed' IQR - interquartile range

Table 2. Patients' health related behaviour

\begin{tabular}{|c|c|c|c|c|c|c|}
\hline & Respondents n (\%) & Rural n (\%) & Urban n (\%) & Males n (\%) & Females n (\%) & Respondents $\mathrm{n}(\%)$ \\
\hline \multicolumn{7}{|l|}{ Number of GP visits in the last 12 months: } \\
\hline 1-2 times & $171(42.8)$ & $72(36.0)$ & $99(49.5)^{* *}$ & $91(45.7)$ & $80(39.8)$ & $171(42.8)$ \\
\hline $3+$ & $229(57.3)$ & $128(64.0)$ & $101(50.5)$ & $108(54.3)$ & $121(60.2)$ & $229(57.3)$ \\
\hline \multicolumn{7}{|l|}{ Smoking status: } \\
\hline current smoker & $120(30.0)$ & $58(29.0)$ & $62(31.0)$ & $74(37.2)$ & $46(22.9)^{* * *}$ & $120(30.0)$ \\
\hline previous smoker & $109(27.3)$ & $57(28.5)$ & $52(26.0)$ & $60(30.2)$ & $49(24.4)$ & $109(27.3)$ \\
\hline \multicolumn{7}{|l|}{ Alcohol consumption status } \\
\hline Not a risky drinker & $384(96.0)$ & $191(95.5)$ & $193(96.5)$ & $188(94.5)$ & $196(97.5)$ & $384(96)$ \\
\hline risky drinker & $16(4.0)$ & $9(4.5)$ & $7(3.5)$ & $11(5.5)$ & $5(2.5)$ & $16(4.0)$ \\
\hline \multicolumn{7}{|l|}{ Declared eating habits: } \\
\hline healthy & $299(74.9)$ & $155(77.9)$ & $144(72.0)$ & $135(67.8)$ & $164(82)$ & $299(74.9)$ \\
\hline \multicolumn{7}{|l|}{ Number of days a week with exercise: } \\
\hline no exercise ( 0 days) & $43(10.8)$ & $31(15.5)$ & $12(6.0) * *$ & $25(12.6)$ & $18(9.0)$ & $43(10.8)$ \\
\hline $1-7$ days & $357(89.3)$ & $169(84.5)$ & $188(94.0)$ & $174(87.4)$ & $183(91.0)$ & $357(89.3)$ \\
\hline $\begin{array}{l}\text { Declared wish for support from GP to increase } \\
\text { physical activity? 'Yes' }\end{array}$ & $96(24.2)$ & $59(29.5)$ & $37(18.8)^{*}$ & 39 (19.6) & $57(28.8)^{*}$ & $96(24.2)$ \\
\hline
\end{tabular}

${ }^{*}-p<0.05 ; *^{* *}-p<0.01 ;{ }^{* * *}-p<0.001$.

for living area comparison, Chi-square test and Chi-square test with Yates correction was employed for a small number of samples.

'Number of visiting GP in last12 months': '3+'=' $3-4$ times' and '5 times or more';

'Smoking status': current smoker as 'I currently smoke'; 'non-smoker'='I have never smoked'; previous smoker as 'I gave up smoking'=I gave up smoking one year ago or less+ I gave up smoking

more than one year ago;

Alcohol consumption status from question: 'How often do you consume alcohol (beer wine or spirits)?': 'not risky drinkers'=never + monthly or less $+2-4$ times a month $+2-3$ times a week; 'risky times a week',

Declared eating habits from question: 'I think my eating habits are': 'not healthy'= Very unhealthy+Rather unhealthy; 'healthy eating'= Relatively health+ Healthy + Very healthy; ('No'= Not applicable. because I control my eating habits+ No+I don't know. 'Yes'= Yes)

Number of days a week with exercise: from question: 'How many days a week do you exercise' 'no exercise' $=0$ days; 'exercise' $=1+2+3+4+5+6+7$ (every day) [in days].

declared by $76.4 \%$ and $72.5 \%$ of rural respondents vs. $89 \%$ and $88 \%$ of urban, respectively.

The flu vaccination was declared as important by $32 \%$ rural vs. $28.1 \%$ urban respondents. Eighty-four percent of rural women regarded a mammogram as important for their health vs. $91.1 \%$ of urban respondents. The area had an effect on prevention importance scores $(\mathrm{p}<0.05$; ICC $=0.0476)$. Area and gender had a statistically significant effect on preventive 
Table 3. Importance of preventive behaviour

\begin{tabular}{|c|c|c|c|c|c|c|}
\hline Importance of: answer: 'important' & Respondents n (\%) & Rural n (\%) & Urban n (\%) & Males $\mathrm{n}(\%)$ & Females n (\%) & Respondents n (\%) \\
\hline healthy eating habits & $325(81.3)$ & $158(79.0)$ & $167(83.5)$ & $147(73.9)$ & $178(88.6)^{* * *}$ & $325(81.3)$ \\
\hline regular physical activity & $319(79.8)$ & $141(70.5)$ & $178(89.0)^{* * *}$ & $153(76.9)$ & $166(82.6)$ & $319(79.8)$ \\
\hline normal body weight & $345(86.3)$ & $161(80.5)$ & $184(92.0) * * *$ & $165(82.9)$ & $180(89.6)^{*}$ & $345(86.3)$ \\
\hline non smoker & $330(82.7)$ & $152(76.4)$ & $178(89.0) * * *$ & $159(80.3)$ & $171(85.1)$ & $330(82.7)$ \\
\hline safe alcohol use or no alcohol use at all & $321(80.3)$ & $145(72.5)$ & $176(88.0) * * *$ & $151(75.9)$ & $170(84.6)^{*}$ & $321(80.3)$ \\
\hline normal blood sugar level & $344(87.1)$ & $162(81.8)$ & $182(92.4) * * *$ & $158(79.4)$ & $186(94.9)^{* * *}$ & $344(87.1)$ \\
\hline normal blood pressure level & $369(92.7)$ & $182(91.0)$ & $187(94.4)$ & $176(88.4)$ & $193(97.0)^{* * *}$ & $369(92.7)$ \\
\hline flu vaccionation & $120(30.1)$ & $64(32.0)$ & $56(28.1)$ & $51(25.8)$ & $69(34.3)$ & $120(30.1)$ \\
\hline having a cervical smear (only for women)? & $186(93.0)$ & $90(90.0)$ & $96(96.0)$ & $0(0.0)$ & $186(93.0)$ & $186(93.0)$ \\
\hline having a mammogram (for women only) & $176(87.6)$ & $84(84.0)$ & $92(91.1)$ & $0(0.0)$ & $176(87.6)$ & $176(87.6)$ \\
\hline
\end{tabular}

$*_{-}-p<0.05 ; *^{* *}-p<0.01 ; *^{* * *}-p<0.001$.

for living area comparison, Chi-square test and Chi-square test with Yates correction was employed for a small number of samples.

'How important for your health is', including answer: important = important+very important.

behaviour importance scores $(\mathrm{p}<0.05$; ICC $=0.0526)$. People living in rural areas scored lower compared to urban, dominant for gender at the 5\% level (rural z-ratio=-2.320). Women scored higher than men in preventive behaviour importance controlling for area of residence at the 5\% level (gender $z$-ratio=6.214). More results on attitudes towards preventive, including gender related data are presented at Table 3.

Predicted mean (mean.pred) prevention importance scores were 0.623 for rural residents $(0.588 .0 .658)$ and 0.682 for urban residents (0.647. 0.717) (Fig 1).

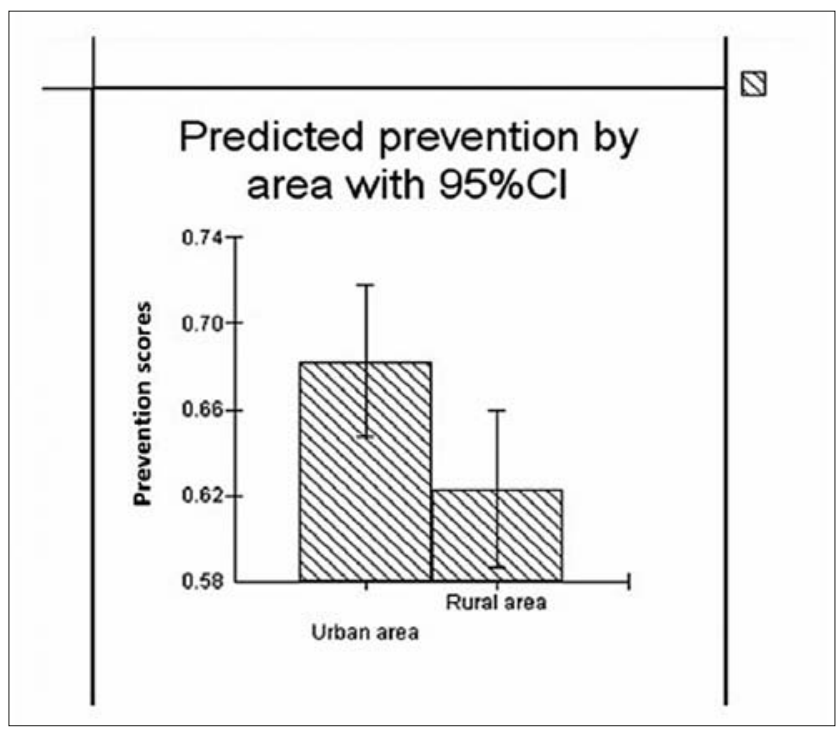

Figure 1. Perceived prevention importance scores by area with $95 \% \mathrm{Cl}$

Predicted mean prevention scores were $0.580(0.543$. 0.617 ) for rural men, $0.667(0.630 .0 .704)$ for rural women, $0.725(0.688 .0 .762)$ for urban women and $0.638(0.601 .0 .675)$ for urban men (Fig. 2).

\section{Declared readiness for action, confidence in access and plan for change}

A total of $56.6 \%$ of rural patients were confident that they would routinely receive the flu vaccination, compared to $72.4 \%$ of urban patients. Of the women, $54.3 \%$ were confident/ sure that they would routinely receive a cervical (pap) smear

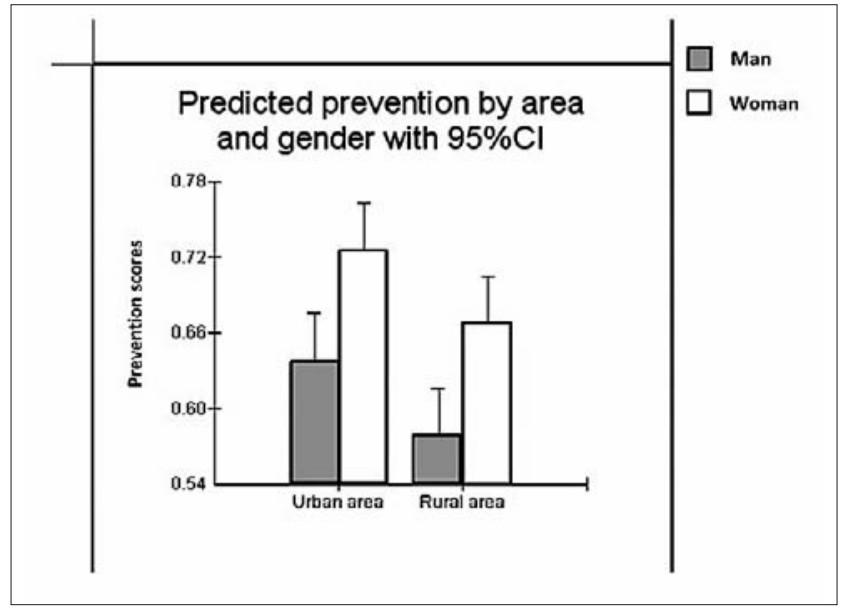

Figure 2. Perceived prevention importance scores by area and gender with $95 \% \mathrm{Cl}$

(63.9\% rural vs. $45.0 \%$ urban) and $59.8 \%$ of rural women vs. $41 \%$ of urban women would routinely receive a mammogram (Tab. 4.). No statistically significant differences were found between area and gender with regard to any perceived need to change lifestyles (eating habits, physical activity, body weight, smoking habit and alcohol use) (Tab. 4)

\section{Support expected from GP / GPs' team}

It was found that $59 \%$ of rural respondents vs. $41 \%$ of urban would like their GP to provide a cervical (pap) smear test; $24.2 \%$ of total respondents (29.5\% rural vs. $18.8 \%$ urban) would like to receive support or advice from their GP regarding increasing physical activity; $31.6 \%$ to improve eating habits; giving up smoking; $17.7 \%$ of the total and only $4.3 \%$ of the total would you like to receive support/advice from a GP to reduce their alcohol use (5.5\% rural vs. 3.1\% urban). The most popular source of support or advice from the GP concerned attaining a normal weight: $36.2 \%$ of the total (38\% rural vs. 34.3 urban). More details on support expected from GP are presented in Table 5.

It was found that $25.8 \%$ of respondents would like to receive from their GP or the GP's team, individual counselling on their eating habits (35.5\% rural vs. 16\% urban); physical activity (22.8\% of all respondents; $32.5 \%$ rural vs. $13 \%$ urban); body weight $(25.3 \%$ of all respondents; $36 \%$ rural vs. $14.5 \%$ urban); smoking cessation (11.3\% of all respondents; $15.0 \%$ 
Table 4. Declared readiness for action, confidence in access and plan for change

\begin{tabular}{|c|c|c|c|c|c|c|}
\hline Declared readiness to answer: 'Yes' & Respondents n (\%) & Rural n (\%) & Urban n (\%) & Males n (\%) & Females n (\%) & Respondents n (\%) \\
\hline improve your eating habits & $187(46.9)$ & $98(49.0)$ & $89(44.7)$ & $90(45.2)$ & $97(48.5)$ & $187(46.9)$ \\
\hline do more physical activity & $165(41.3)$ & $91(45.5)$ & $74(37.0)$ & $76(38.2)$ & $89(44.3)$ & $165(41.3)$ \\
\hline improve body weight & $176(44.0)$ & $87(43.5)$ & $89(44.5)$ & $78(39.2)$ & $98(48.8)^{*}$ & $176(44.0)$ \\
\hline stop smoking & $86(21.5)$ & $43(21.5)$ & $43(21.5)$ & $54(27.1)$ & $32(15.9)^{* * *}$ & $86(21.5)$ \\
\hline reduce alcohol use & $25(6.3)$ & $12(6.0)$ & $13(6.5)$ & $20(10.1)$ & $5(2.5)^{* * *}$ & $25(6.3)$ \\
\hline have blood sugar checked & $275(68.9)$ & $134(67.3)$ & $141(70.5)$ & $137(68.8)$ & $138(69.0)$ & $275(68.9)$ \\
\hline have blood pressure checked & $298(74.5)$ & $145(72.5)$ & $153(76.5)$ & $144(72.4)$ & $154(76.6)$ & $298(74.5)$ \\
\hline get a flu vaccination & $108(27.1)$ & $50(25.0)$ & $58(29.2)$ & $53(26.8)$ & $55(27.4)$ & $108(27.1)$ \\
\hline get a cervical (pap) smear & $140(70.4)$ & $69(69.0)$ & $71(71.7)$ & $0(0.0)$ & $140(70.4)$ & $140(70.4)$ \\
\hline get a mammogram (for women only) & $136(67.7)$ & $61(61.0)$ & $75(74.3)^{*}$ & $0(0.0)$ & $136(67.7)$ & $136(67.7)$ \\
\hline the flu vaccination & $256(64.5)$ & $112(56.6)$ & $144(72.4)^{* * *}$ & $128(64.3)$ & $128(64.7)$ & $256(64.5)$ \\
\hline a cervical (pap) smear & $107(54.3)$ & $62(63.9)$ & $45(45.0)^{* *}$ & $0(0.0)$ & $107(54.3)$ & $107(54.3)$ \\
\hline a mammogram (for women only) & $99(50.3)$ & $58(59.8)$ & $41(41.0)^{* *}$ & $0(0.0)$ & $99(50.3)$ & $99(50.3)$ \\
\hline \multicolumn{7}{|l|}{ Plan to change: answer: "Yes" } \\
\hline eating habits & $136(34.1)$ & $67(33.7)$ & $69(34.5)$ & $60(30.3)$ & $76(37.8)$ & $136(34.1)$ \\
\hline physical activity & $108(27.1)$ & $54(27.1)$ & $54(27.0)$ & $42(21.2)$ & $66(32.8)^{* * *}$ & $108(27.1)$ \\
\hline body weight & $156(39.1)$ & $76(38.2)$ & $80(40.0)$ & $66(33.3)$ & $90(44.8)^{* *}$ & $156(39.1)$ \\
\hline smoking habit & $64(16.1)$ & $28(14.1)$ & $36(18.2)$ & $43(21.7)$ & $21(10.6)^{* * *}$ & $64(16.1)$ \\
\hline alcohol use & $17(4.3)$ & $8(4.0)$ & $9(4.6)$ & $14(7.1)$ & $3(1.5)^{* *}$ & $17(4.3)$ \\
\hline
\end{tabular}

${ }^{*}-p<0.05 ;{ }^{* *}-p<0.01 ; * * *-p<0.001$.

for living area comparison, Chi-square test and Chi-square test with Yates correction was employed for a small number of samples.

'How confident/sure are you that you can/could routinely receive the following care': including answers 'Confident'.

Table 5. Areas and means of support expected from GP/ GPs' team.

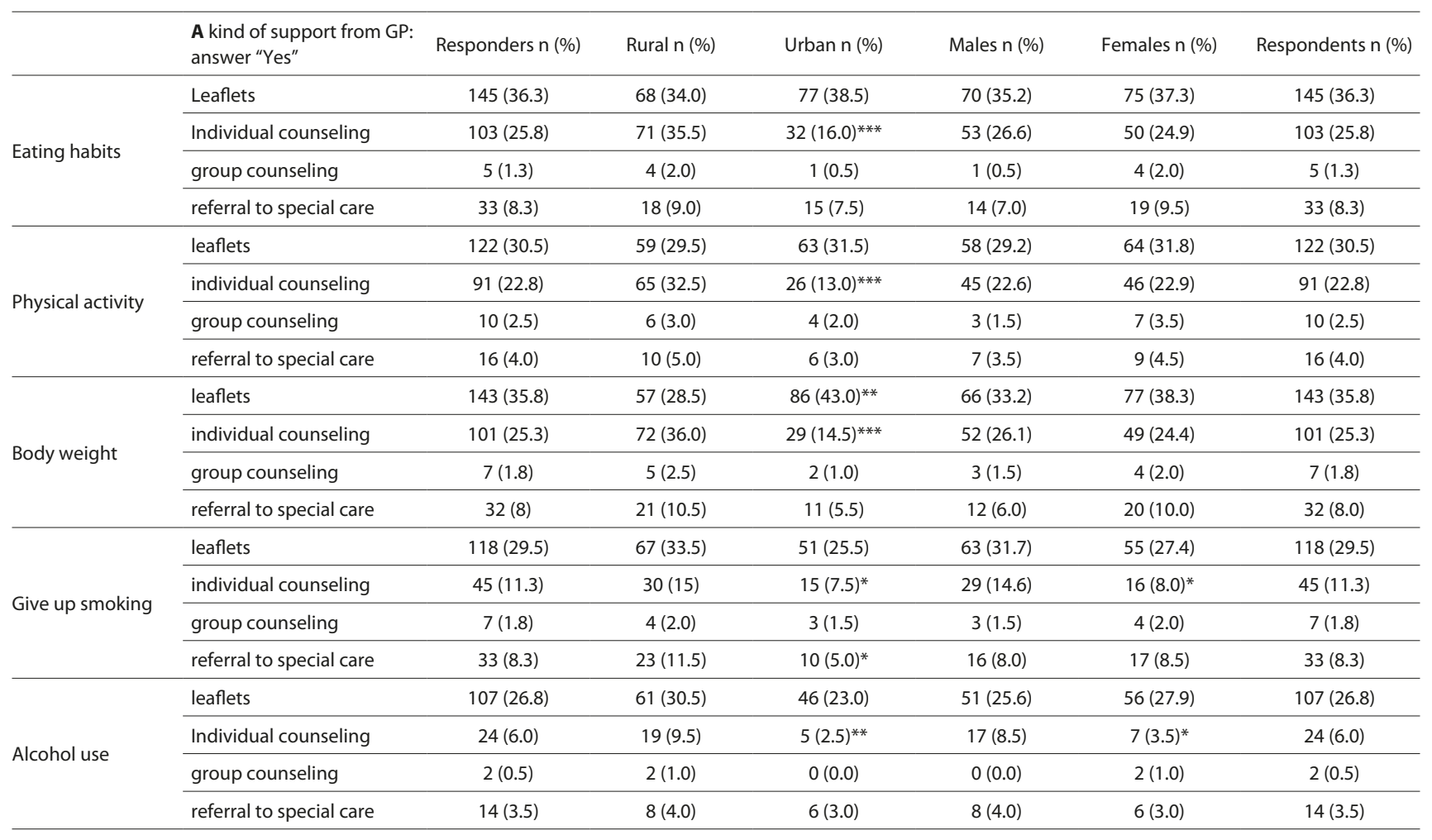

$*_{-} \mathrm{p}<0.05 ; * *_{-} \mathrm{p}<0.01 ; * *{ }^{*} \mathrm{p}<0.001$

for area of residence comparison, Chi-square test and Chi-square test with Yates correction was employed for a small number of samples.

'If you want support - what kind of support would you like to receive from your GP/team?' - answer 'Yes' by living area. 
rural vs. $7.5 \%$ urban); and alcohol use reduction $(6 \%$ of all respondents; rural $9.5 \%$ vs. urban 2.5$) \%$. Out of $26.8 \% \%$ of risky drinkers, $30.5 \%$ of rural and $23 \%$ of urban participants would like to receive support in the form of information leaflets. In addition, $38 \%$ of rural men would like individual counselling on improving their eating habits and $38 \%$ on normalizing their body weight $(\mathrm{p}<0.0001)$; and $33 \%$ of rural men on regular their physical activity vs. rural women. However, $35.8 \%$ of total respondents would like access to information leaflets regarding normalizing body weight: $28.5 \%$ people in rural areas (26\% rural men vs. $31 \%$ rural women) vs. $43.0 \%$ in urban areas (45.5\% urban women vs. $40.4 \%$ urban men). Only $0.5 \%$ of total respondents would like group counselling to reduce their alcohol use: $1 \%$ in rural and nobody in urban areas (Chi-Squared Yates correction). Regarding giving up smoking, $11.5 \%$ of rural inhabitants vs. $5 \%$ of urban residents would like a referral to special care.

\section{DISCUSSION}

Countries face challenges in eliminating health risks and discrepancies associated with factors such as ethnicity, gender, culture, health literacy and access to health care facilities. Efforts to address these issues in rural settings were initiated in the mid-1990s [12, 13], and this was soon followed by rural-based preventive research which set an agenda for this field and identified related topics $[14,15]$. A wide range of rural prevention research needs were identified through this process, including barriers to the implementation of intervention in rural areas [16].

The presented study focuses on the geographic and gender aspects of preventive care in Poland where rural residents constituted $38.8 \%$ of total population at the time of the study [17]. A difference in respondent education level needs to be noted which could bias the results. More rural respondents smoked. Urban patients visited their GPs more often and seemed to take part in more exercise, while more rural respondents declared only an intention to do so. In both locations, most respondents reported that preventive behaviour was important. However, slightly more so in urban areas; the rural population reported a greater need for flu vaccination. Rural respondents were more confident about routine access to flu vaccination, and urban women to cervical smear and mammography.

No difference was found between areas of residence with regard to confidence in ability to improve eating habits, increasing physical activity, attaining a normal weight, quitting smoking or reducing alcohol intake. Less than half of the respondents planned to change their preventive, healthrelated behaviour, with no significant difference observed between locations. More respondents planned to change body weight, compared to those who wanted to improve eating and smoking habits, or increasing physical activity. Generally, one in three respondents expected some support from the GP/GPs team. Rural respondents received such support in healthy eating habits (in the form of individual counselling, group counselling and referral to special care), in physical activity (with information leaflets), in body weight control (with information leaflets and group counselling), to give up smoking (with information leaflets. individual counselling and in alcohol use (with information leaflets. individual counselling. group counselling) and referral to special care.
The gender difference was in line with study findings in the USA which indicated that women were more proactive in their health beliefs towards preventive care and getting regular check-ups than men [18]. In general, it seems that Polish patients assigned great importance to preventive care with a relatively low level of willingness to change their lifestyle. Rural residents assigned a lower importance to prevention with less willingness to change their lifestyle than city dwellers. The expectation of GP assistance guidance was higher in rural areas than in urban areas.

The current study shared the limitations of international studies Lifestyle habits were self-reported by patients and could thus be inaccurate or biased. Common problems could be under-reporting of true lifestyle traits or under-reporting of the advice given during their practice visits, either because of the sensitivity of some of the lifestyle areas or simply due to forgetfulness. Patients might find it hard to quantify their behaviour measures. Primary care teams that took part in the study may have been more interested and motivated to address lifestyle risk factors compared to other teams, and also may have not provided a representative sample of patients. The generalizability of the results could have been influenced by the participation rate of those invited. Another limitation was the sample size.

On the other hand, an important strength of the survey was that it was performed in a community whch hopefully reflected the picture of the general population by using standardized methods. The study raised a number of health promotion and prevention issues of interest to primary health care providers in Poland and elsewhere.

\section{CONCLUSIONS}

Place of residence, urban or rural, plays a role in patients' attitude towards preventive care and can potentially determine health choices. The understanding of gender and social circumstances may reinforce the ability of the GP to act and help overcome some of these identified obstacles. One of these is health illiteracy which may prevent a person from following health instructions. The strong association between illiteracy and poverty may exert powerful negative influences on health outcomes. Therefore, family physicians need a deeper understanding of patients' beliefs prior to promoting certain health interventions.

The participants in this study assigned high importance to prevention, with little readiness to change lifestyle. People living in rural areas assigned a lower level of importance to prevention and with less willingness to change their lifestyle than residents living in urban areas. Rural patients expected more support from their GP, such as individual counselling, than urban patients, regarding eating habits, physical activity, body weight and giving up smoking.

\section{Acknowledgements}

The authors express their gratitude to the European Society of General Practice/Family Medicine and to Unilever for grants to complete this study. Thanks are also due to the health professionals and patients who participated.

\section{Ethics}

This anonymous survey did not require ethical approval in Poland. Participation in the survey was voluntary and written 
informed consent was obtained from every participant before the questionnaire was completed. No sensitive personal data were collected. Data was made anonymus and confidentiality maintained by data coding to eliminate identification of data with personal information.

\section{REFERENCES}

1. Wonca Working Party on Rural Practice, W.O.o.F.D., Policy on Rural Practice and Rural health. Wonca, World family doctors Caring for people, 2001.

2. Jacobs B, et al. Addressing access barriers to health services: an analytical framework for selecting appropriate interventions in lowincome Asian countries. Health Policy and Planning Advance Access 2011: p. 1-13.

3. Spasojevic N, et al. Rural - urban differences in health care quality assessment. Materia socio-medica 2015; 27(6): p. 409-11.

4. Peters, D.H., et al., Poverty and access to health care in developing countries. Reducing the Impact of Poverty on Health and Human Development: Scientific Approaches, 2008; 1136: p. 161-171.

5. Anderson TJ, et al. A cross-sectional study on health differences between rural and non-rural U.S. counties using the County Health Rankings. BMC Health Services Res. 2015; 15: p. 441.

6. Probst JC, et al. Effects of residence and race on burden of travel for care: cross sectional analysis of the 2001 US National Household Travel Survey. BMC Health Services Res. 2007; 7.

7. Smith CM, Yawn BP. Factors Associated with Appointment Keeping in a Family-Practice Residency Clinic. J Fam Prac. 1994; 38(1): p. 25-29.
8. Spasojevic N, Hrabac B, Huseinagic S. Patient's Satisfaction with Health Care: a Questionnaire Study of Different Aspects of Care. Materia Socio-Med. 2015; 27(4): p. 220-4.

9. Williams F, et al. Rural-urban difference in female breast cancer diagnosis in Missouri. Rural Remote Health. 2015; 15(3): p. 3063.

10. Brotons, C., et al., Attitudes toward preventive services and lifestyle: the views of primary care patients in Europe. The EUROPREVIEW patient study. Family Pract. 2012; 29: p. i168-i176.

11. Acts of Laws, [Ustawa z dnia 29 sierpnia 2003 r. o urzędowych nazwach miejscowości i obiektów fizjograficznych.] Acts of Laws No. 166 i, as amended. edited. The Act of 29 August 2003 on the official names of localities and physiographic objects. 2003. Dz.U. z 2003 r. Nr 166, poz. 1612 - Opublikowano 22 września 2003 r., 2003.

12. Muehrer P. Introduction to the special issue: Mental health prevention science in rural communities and contexts. Am J Comm Psychol. 1997; 25(4): p. 421-424.

13. Robertson EB, Sloboda Z, Boyd GM. Beatty L, Kozel NJ. Rural Substance Abuse: State of Knowledge and Issues. NIDA Res Monograph 168., 1997, National Inst. on Drug Abuse (DHHS/PHS), Rockville, MD.

14. Robertson EB. Introduction: Interventions and Services. U.S. Department of Health and Human Services. Rockville. NIDA Prevention, NIH Publication No. 97-4177. 1997; p. 246-249.

15. Spoth R. Opportunities to meet challenges in rural prevention research: Findings from an evolving community-university partnership model. J Rural Health. 2007; 23: p. 42-54.

16. StLawrence JS, Ndiaye SM. Prevention research in rural communities: Overview and concluding comments. Am J Comm Psychol. 1997; 25(4): p. 545-562.

17. The worldbank data, https://data.worldbank.org/indicator.

18. Ray-Mazumder, S., Role of gender, insurance status and culture in attitudes and health behavior in a US Chinese student population. Ethnicity Health. 2001; 6(3-4): p. 197-209. 